\title{
Effect of Different Salinization Methods of Silica Filler on Rubber Reinforcement
}

\author{
Nur Haslina Nasirah Abdul Hadi, Azila Anuar and Raa Khimi Shuib* \\ School of Materials and Mineral Resources Engineering, Universiti Sains \\ Malaysia, Engineering Campus, 14300 Nibong Tebal, Pulau Pinang, Malaysia \\ *Corresponding author: raakhimi@usm.my
}

Published online: 31 December 2019

To cite this article: Nur Haslina Nasirah Abdul Hadi, Azila Anuar and Raa Khimi Shuib (2019). Effect of different salinization methods of silica filler on rubber reinforcement. Journal of Engineering Science, 15(2), 71-81, https://doi.org/10.21315/jes2019.15.2.5

To link to this article: https://doi.org/10.21315/jes2019.15.2.5

\begin{abstract}
The main objective of this work was to investigate the effects of three different methods of surface modification using bis-(3-triethoxysilylpropyl) tetrasulfide (TESPT) on silica filler to improve silane linkages between rubber matrix and filler. The filler was treated with silane coupling agent using aqueous, dry, and integral blend methods. Evidence that coupling agent had occurred between fillers and TESPT was identified by Fourier transform infrared spectroscopy (FTIR). The results exhibited the advantages of TESPT as a coupling agent between fillers particles and rubber also revealed that silica has better dispersion in dry method. The effects of different surface modification methods on mechanical properties and morphological characteristics of natural rubber were also investigated.
\end{abstract}

Keywords: rubber, silane coupling agent, silica, TESPT

\section{INTRODUCTION}

The performance of rubber materials is greatly affected by the dispersion of reinforcing fillers. Almost all rubber materials are produced with the addition of filler particles. ${ }^{1}$ The most commonly used inorganic fillers are silica, fibres, ferrite, talc, and calcium carbonate. ${ }^{2-5}$ Major problems in the incorporation of the inorganic fillers in the rubber materials are the incompatibility, poor wettability, and weak adhesion between the filler and rubber as well as the non-uniformity of filler dispersion leading to poor physical and mechanical properties. In order to solve these problems, addition of coupling agent is required to ensure the production of final product having high performance. ${ }^{1,6}$ 
Bifunctional coupling agent such as bis-(3-triethoxysilylpropyl) tetrasulphide (TESPT) is by far the most popular and effective coupling agent for hydrocarbon rubber. The TESPT is an organic silane with ethoxy hydrolysable groups at both ends which enable the silicon groups to bond with inorganic fillers and tetrasulphane groups $\left(\mathrm{S}_{4}\right.$ ring) of its centre capable to form crosslink with the rubber molecule chains. Although this type of surface modification is established for enabling different types of fillers such as silica, iron sand, halloysite nanotubes, wood flour, and natural fibre to be used as reinforcement fillers in rubber composites..$^{7-11}$ However, the effective processing method to apply TESPT to the inorganic fillers has not been extensively studied.

Therefore, in this work, three different methods namely, aqueous, dry, and integral blending methods were used for surface treatment of TESPT. Evidence of silane coupling agent between fillers and TESPT was verified by Fourier transform infrared spectroscopy (FTIR). Crosslink density assessment and tensile properties of the rubber composites were measured to evaluate the interfacial interaction between the fillers and the rubber matrix.

\section{EXPERIMENTAL DETAILS}

\subsection{Materials}

Natural rubber (Standard Malaysia Rubber [SMR] L grade) and other chemicals including zinc oxide, stearic acid, n-cyclohexyl-2-benzothioazole sulfonamide (CBS), tetramethylthiuram disulphide (TMTD), and n-isopropyl-n'phenyl-p-phenylenediamine (IPPD) were all purchased from Zarm Scientific \& Supplies Sdn. Bhd. (Pulau Pinang, Malaysia). TESPT was purchased from Leap LabChem Co. Ltd. (China). Precipitated silica (Grade Vulkasil S) with density $2.0967 \mathrm{~g} \mathrm{~cm}^{-3}$ and average particle size of $22 \mathrm{~nm}$ was supplied by Bayer Co. (M) Sdn. Bhd. (Pulau Pinang, Malaysia).

\subsection{Surface Modification of Fillers Particles}

\subsubsection{Aqueous method}

The surface modification of fillers was carried out using an aqueous alcohol solution method. The fillers were subjected to surface treatment with TESPT at $6 \%$ by weight (wt\%) of the fillers. An aqueous alcohol solution of $95 \%$ ethanol was used, and the $\mathrm{pH}$ of the solution was adjusted with acetic acid to 4.0-4.5. The TESPT of predetermined quantity was dispersed in the ethanol solution at a ratio 
of 1:100 and the mixed solution was stirred for $5 \mathrm{~min}$ to assure the hydrolysation of the silane coupling agent. The fillers were then added and stirred for an additional $30 \mathrm{~min}$ at room temperature to ensure a uniform distribution of the coupling agent on the surface of the fillers. The mixture was filtered and washed three times with ethanol to remove unreacted coupling agent. The treated fillers were then dried at $80^{\circ} \mathrm{C}$ in an oven until constant weight was achieved.

\subsubsection{Dry method}

In dry method, the TESPT silane coupling agent was added at full strength and evenly dispersed in the fillers as it was mixed at high speed mixer. Firstly, the fillers of predetermined quantity were added in a container of rotating mixer. After this, $1 \mathrm{wt} \%$ of water was then added to the fillers and the container of rotating mixer was closed to minimise contact with air and let it sit for $8 \mathrm{~h}$ at a temperature of $50^{\circ} \mathrm{C}$. This promotes even dispersion of the water on the filler surface. Then, the wet fillers were subjected to surface treatment with TESPT at $6 \mathrm{wt} \%$ relative to the weight of the fillers. The TESPT was added in the container and the mixture was mixed at 200-250 rpm for $4 \mathrm{~h}$ using rotating mixer. Finally, the treated fillers were dried at $80^{\circ} \mathrm{C}$ in an oven until a constant weight was achieved.

\subsubsection{Integral blend methods}

In integral blend method the TESPT silane coupling agent was used as a simple additive during mixing and compounding of the rubber and other ingredients in a conventional laboratory two roll mill (XK 160). TESPT at $6 \mathrm{wt} \%$ relative to the weight of the particle was added to the rubber compound. The addition of the TESPT was carried out after the fillers were uniformly dispersed in the rubber compound to prevent agglomeration. The mixing and compounding process and sequence of addition of the additives are explained in the next section.

\subsection{Preparation of Rubber Composites}

The compound formulation used in this study is given in Table 1. Formulations were compounded using a conventional laboratory two roll mill (model XK-160). The compounding began with mastication of rubber on two roll mill for 2-3 min. After mastication, the rubber had become invested on the hot roll, additives (zinc oxide, stearic acid, and IPPD) were then added followed by treated fillers (silica, ferrite, and kenaf) for both aqueous and dry methods or untreated fillers followed by TESPT for integral method. The addition of accelerators (CBS and TMTD) and sulphur were delayed to the last part of the process to prevent premature vulcanisation during compounding. The mixing time was approximately 
30 min. The cure time (t90) was then determined using an MDR 2000 Mosarto Moving Die Rheometer (Akron, OH, USA) according to ISO 3417 at $150^{\circ} \mathrm{C}$. Compounded rubber samples weighing $35 \mathrm{~g}$ were placed in a mould $(152 \times 123$ $\times 2 \mathrm{~mm}^{3}$ ) and were cured in a compression moulder at $150^{\circ} \mathrm{C}$ under a pressure of approximately $12 \mathrm{Mpa}$.

Table 1: Formulation of rubber compound.

\begin{tabular}{lcc}
\hline \multirow{2}{*}{ Material } & \multicolumn{2}{c}{ Loading $\left(\mathrm{phr}{ }^{*}\right)$} \\
\cline { 2 - 3 } & Aqueous, dry, and integral methods & Control sample \\
\hline Natural rubber (SMR L grade) & 100 & 100 \\
Zinc oxide & 5 & 5 \\
Stearic acid & 1 & 1 \\
IPPD & 2 & 2 \\
Silica & 50 & 50 \\
TESPT (wt\%) & 6 & 0 \\
CBS & 2 & 2 \\
TMTD & 1 & 1 \\
Sulphur & 1.5 & 1.5 \\
\hline
\end{tabular}

Note: *phr = per hundred rubber

\section{$2.4 \quad$ FTIR}

FTIR was recorded using a Perkin Elmer Spectrum instrument (Massachusetts, USA) under an inert air atmosphere, to investigate the inorganic fillers and rubber interaction in the compounds at different treatment methods. The FTIR measurements were performed directly on the final cast rubber composites, and the spectral range was from 900 to $3,500 \mathrm{~cm}^{-1}$. Five separate spectra were acquired at different locations on each sample analysed.

\subsection{Morphology}

The fracture surfaces of the rubber composites were examined using a field emission scanning electron microscope (FE-SEM model Zeiss SUPRA 35VP, Berlin, Germany). The samples were immersed in liquid nitrogen to frozen and subsequently snapped into pieces to expose the interior of fractured surface. The fracture surface was coated with gold prior to observation at an acceleration voltage of $10 \mathrm{kV}$. 


\subsection{Tensile Properties}

The tensile tests were performed at room temperature using an Instron testing machine (Model 3366, Massachusetts, USA) according to the ASTM D624 standard test method at a crosshead speed of $500 \mathrm{~mm} \mathrm{~min}^{-1}$. Dumbbell tensile specimens (gauge length of $50 \mathrm{~mm}$ and width of $6.4 \mathrm{~mm}$ and thickness of $2 \mathrm{~mm}$ ) were used for the test. Tensile strength, Young's modulus, and elongation at break were determined. Five specimens for each set of material were tested.

\section{RESULTS AND DISCUSSION}

\section{1 $\quad$ FTIR}

FTIR spectra analysis of rubber filled with untreated and treated silica using different silane treatment methods is shown in Figure 1. For untreated silica filled rubber composites, rubber can be identified by two characterisation peaks around 2,920 and 2,850 $\mathrm{cm}^{-1}$ assigned to the $\mathrm{C}-\mathrm{H}$ stretching vibrations. More peaks are observed at 1,375 and $1,465 \mathrm{~cm}^{-1}$ and are assigned to $\mathrm{CH}_{2}$ stretching, and $\mathrm{CH}_{3}$ and $\mathrm{CH}_{2}$ bending, respectively. ${ }^{12}$ Silica in the composites can be identified from strong stretching vibrations of the siloxane ( $\mathrm{Si}-\mathrm{O}-\mathrm{Si})$ bond at $1,100 \mathrm{~cm}^{-1}$, and a small peak at $950 \mathrm{~cm}^{-1}$ assigned to $\mathrm{Si}-\mathrm{O}$ stretching, indicating the presence of some silanol $(\mathrm{Si}-\mathrm{OH})$ groups. ${ }^{13}$ After silica filler rubber composites treated with TESPT, the FTIR spectra show that most of the silanols $(\mathrm{Si}-\mathrm{OH})$ reacted to form $\mathrm{Si}-\mathrm{O}-\mathrm{Si}$ bonds. The increment of intensity and shift of peak at $1,100 \mathrm{~cm}^{-1}$ are the evidence of interactions. Based on the different processing method it is clear that both aqueous and dry methods show better interaction between silica and rubber than integral method. 


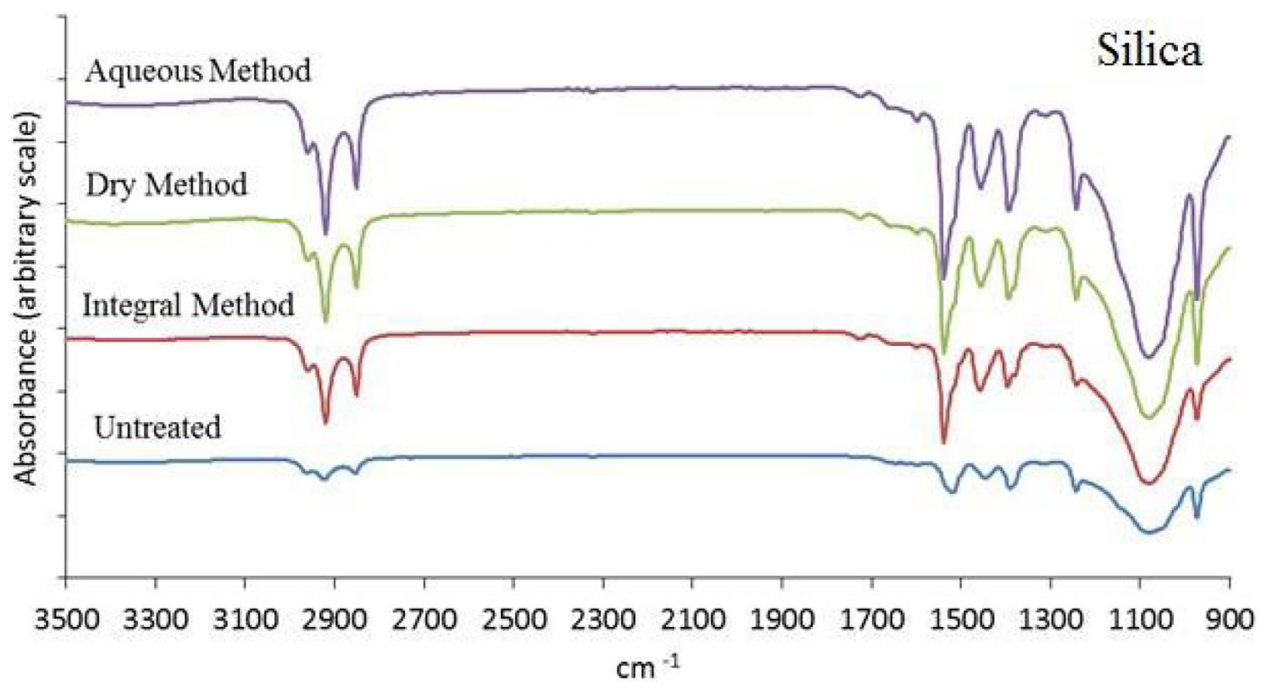

Figure 1: FTIR spectra of silica filled rubber composites using different TESPT treatment methods.

\subsection{Morphology}

To evaluate the dispersion of fillers and the rubber matrix, the morphologies of the fractured surface of rubber with untreated and treated silica using different silane treatment methods are presented in Figure 2. As shown in Figure 2(a), the fractured surface of untreated silica filled rubber composite exhibits a relatively rough surface with uneven distribution of silica particles. In addition, agglomerate areas of several micrometres can be clearly found in the silica dispersed in the rubber. After the silane treatment of silica, the fractured surface of composites exhibits better dispersion, the agglomerates were effectively broken and uniform distribution by using silane treatment of aqueous and dry methods as shown in Figure 2(b) and 2(c). In Figure 2(d) for the treated silica using integral method, the dispersion of the fillers was improved but some of silica particles agglomerate can be observed. In general, dry method shows the best dispersion for silica filler in the rubber matrix. 

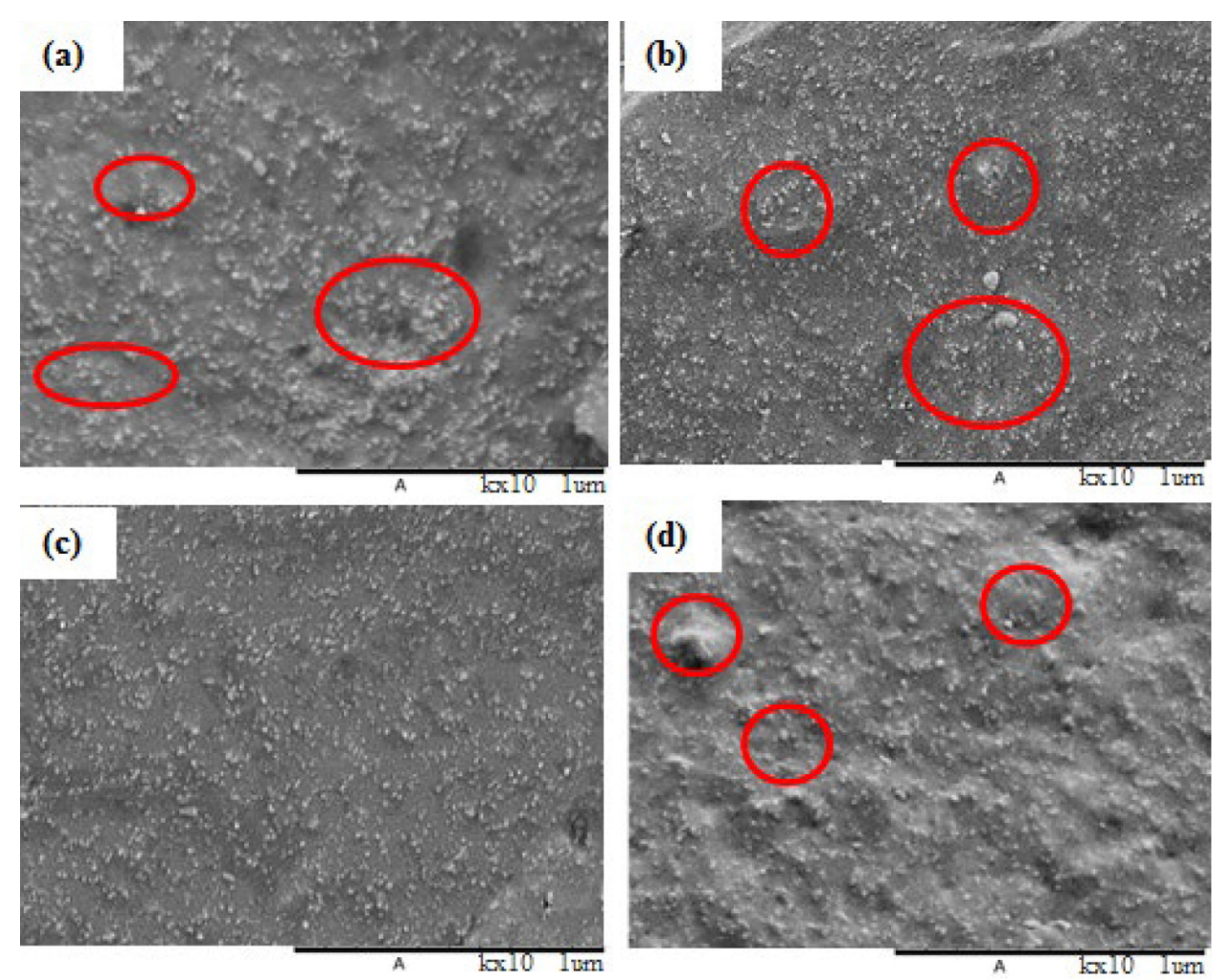

Figure 2: SEM images of fractured surface: (a) untreated, (b) aqueous, (c) dry, and (d) integral blend methods for silica filled rubber composites.

\subsection{Tensile Properties}

The effect of silica filler on the tensile properties of rubber composites using different TESPT treatment methods are shown in Figure 3. As seen in Figure 3(a), treated silica showed an increment in the tensile strength compared to those of the untreated rubber composites. Two main factors can explain the increment in the tensile strength of the TESPT treated silica compared to untreated rubber composites. First, the silane functional groups can produce strong filler-rubber bonding and thus improve their stress transferring efficiency, leading to increase in tensile strength. In addition, the silanol group grafted onto the surface of fillers can prevent stacking and aggregation of fillers, thus, improve the dispersion state of filler in rubber matrix. ${ }^{14}$ Second, the dispersion methods used for silane treated silica in the rubber matrix are the most important factor to be considered. Comparatively, both aqueous and dry methods showed high tensile strength than integral method due to stronger interaction and uniform dispersion of silica. 


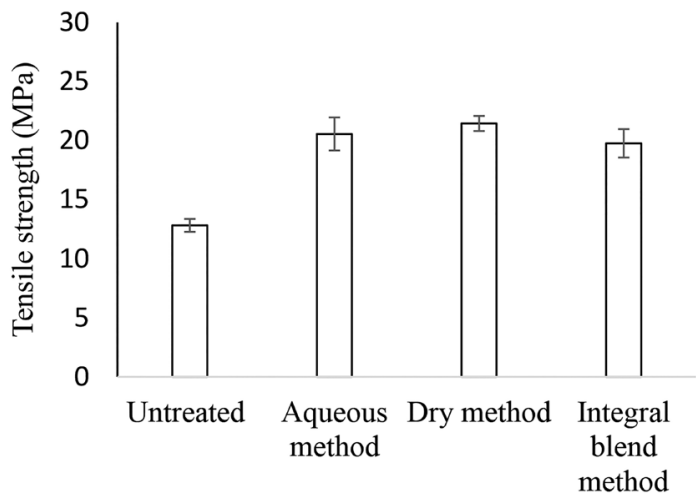

(a)

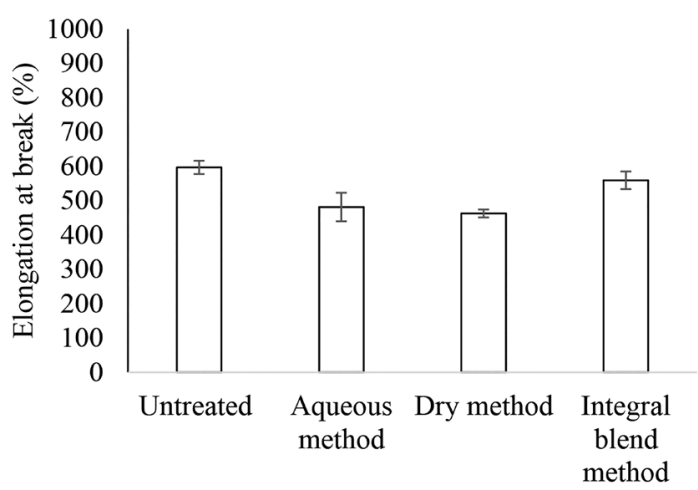

(b)

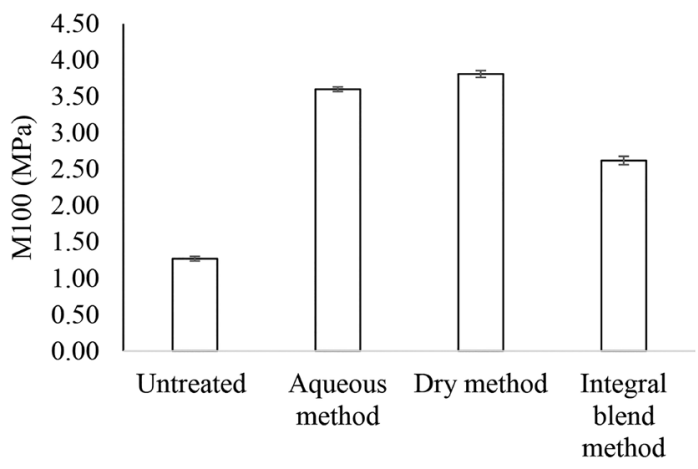

(c)

Figure 3: Tensile properties of silica filled rubber composites using different TESPT treatment methods: (a) tensile strength, (b) elongation at break, and (c) modulus M100. 
The elongation at break of silica filled rubber composites using different TESPT treatment methods are shown in Figure 3(b). Addition of silica showed decrement in the elongation at break compared to those of the untreated rubber composites. This was because the natural rubber matrix grew stronger and stiffer with inclusion of the treated fillers and resulted in a lower elongation. ${ }^{15}$ The most probable explanation for the lower elongation at break for the samples prepared in the presence of TESPT is that TESPT probably settled on the interface between the silica particles and rubber matrix and did not form part of the network. In contrast to tensile strength, both aqueous and dry methods showed lower elongation at break compared to integral method. The higher elongation at break for integral method maybe attributed to poor interaction between fillers and rubber matrix that led to increase in the elongation at break.

The M100 of silica filled rubber composites using different TESPT treatment methods exhibited the same trend as the tensile strength. As shown in Figure 3(c), treated fillers filled rubber composites showed an increment in the modulus M100 compared to those of the untreated rubber composites. The improvement in tensile modulus, associated with the addition of a coupling agent, has been reported in the past. ${ }^{16}$ The presence of silane coupling agent reduces the chain mobility and increase rigidity of the treated rubber composites. Thus, exhibit high modulus M100 of the composites. ${ }^{17}$ Moreover, the dry method has the highest M100 followed by aqueous and integral methods.

\section{CONCLUSION}

In this work, silica filler was successfully modified with TESPT using aqueous, dry, and integral blend methods. FTIR spectra showed that the silanols $(\mathrm{Si}-\mathrm{OH})$ reacted to form $\mathrm{Si}-\mathrm{O}-\mathrm{Si}$ bonds. The intensity peak of FTIR spectra revealed that aqueous and dry methods had better interaction between silica and rubber than integral blend method. FTIR results were supported with SEM of the fractured surface where the filler distribution was improved with less agglomeration within the rubber matrix. It was also found that dry method had the highest tensile strength and M100 compared with aqueous and integral blend methods. However, the elongation at break was found to be the lowest compared to other methods, which could be explained due to reduce the chain mobility and increase rigidity of the treated rubber composites. 


\section{ACKNOWLEDGEMENTS}

The authors gratefully acknowledge support from the Ministry of Education Malaysia under FRGS Grant 6071349.

\section{REFERENCES}

1. Stöckelhuber, K. W., Das, A., Jurk, R. \& Heinrich, G. (2010). Contribution of physico-chemical properties of interfaces on dispersibility, adhesion and flocculation of filler particles in rubber. Polym., 51(9), 1954-1963, https://doi.org/10.1016/j.polymer.2010.03.013.

2. Romli, A. Z. \& Ghaztar, M. M. M. (2017). The fibre damage due to the mechanical cutting of treated and untreated kenaf short fibre/unsaturated polyester composite. J. Eng. Sci., 13, 63-74, https://doi.org/10.21315/ jes2017.13.5.

3. Shuib, R. K. \& Pickering, K. L. (2016). Effect of carbon black on the dynamic properties of anisotropic magnetorheological elastomer. J. Eng. Sci., 12, 1-12.

4. Zainal, N. A., Shukor, S. R. A. \& Razak, K. A. (2015). Applying the Taguchi method to optimise the size of silica nanoparticles entrapped with rifampicin for a drug delivery system. J. Eng. Sci., 11, 9-16.

5. Vincent, S. R., Jaafar, M. \& Palaniandy, S. (2014). Properties of calcium carbonate/MICA and calcium carbonate/talc filled polypropylene composites. J. Eng. Sci., 10, 41-47.

6. Qu, L., Yu, G., Xie, X., Wang, L., Li, J. \& Zhao, Q. (2013). Effect of silane coupling agent on filler and rubber interaction of silica reinforced solution styrene butadiene rubber. Polym. Compos., 34(10), 1575-1582, https://doi.org/10.1002/pc.22554.

7. Kaewsakul, W., Sahakaro, K., Dierkes, W. K. \& Noordermeer, J. W. (2015). Mechanistic aspects of silane coupling agents with different functionalities on reinforcement of silica-filled natural rubber compounds. Polym. Eng. Sci., 55(4), 836-842, https://doi.org/10.1002/pen.23949.

8. Pickering, K. L. Khimi, S. R. \& Ilanko, S. (2015) The effect of silane coupling agent on iron sand for use in magnetorheological elastomers Part 1: Surface chemical modification and characterization. Compos. Part A-Appl. S., 68, 377-386, https://doi.org/10.1016/j.compositesa.2014.10.005.

9. Raman, V., Rooj, S., Das, A., Stöckelhuber, K., Simon, F., Nando, G. \& Heinrich, G. (2013). Reinforcement of solution styrene butadiene rubber by silane functionalized halloysite nanotubes. J. Macromol. Sci. A, 50(11), 1091-1106, https://doi.org/10.1080/10601325.2013.829349. 
10. Ismail, H. \& Khalil, H. A. (2000). The effects of partial replacement of oil palm wood flour by silica and silane coupling agent on properties of natural rubber compounds. Polym. Test., 20(1), 33-41, https://doi.org/10.1016/ S0142-9418(99)00075-6.

11. Zeng, Z., Ren, W., Xu, C., Lu, W., Zhang, Y. \& Zhang, Y. (2009). Effect of bis (3-triethoxysilylpropyl) tetrasulfide on the crosslink structure, interfacial adhesion, and mechanical properties of natural rubber/cotton fiber composites. J. Appl. Polym. Sci., 111(1), 437-443, https://doi. org/10.1002/app.29028.

12. Mokhothu, T., Luyt, A. \& Messori, M. (2014). Reinforcement of EPDM rubber with in situ generated silica particles in the presence of a coupling agent via a sol-gel route. Polym. Test., 33, 97-106, https://doi. org/10.1016/j.polymertesting.2013.11.009.

13. Mokhothu, T., Luyt, A. \& Messori, M. (2014). Preparation and characterization of EPDM/silica nanocomposites prepared through nonhydrolytic sol-gel method in the absence and presence of a coupling agent. Express Polym. Lett., 8(11), 809-822, https://doi.org/10.3144/ expresspolymlett.2014.83.

14. Kango, S., Kalia, S., Celli, A., Njuguna, J., Habibi, Y. \& Kumar, R. (2013). Surface modification of inorganic nanoparticles for development of organic-inorganic nanocomposites: A review. Prog. Polym. Sci., 38(8), 1232-1261, https://doi.org/10.1016/j.progpolymsci.2013.02.003.

15. Lopattananon, N., Jitkalong, D. \& Seadan, M. (2011). Hybridized reinforcement of natural rubber with silane-modified short cellulose fibers and silica. J. Appl. Polym. Sci., 120(6), 3242-3254, https://doi. org/10.1002/app.33374.

16. Ismail, H., Shuhelmy, S. \& Edyham, M. R. (2002). The effects of a silane coupling agent on curing characteristics and mechanical properties of bamboo fibre filled natural rubber composites. Eur. Polym. J., 38(1), 39-47, https://doi.org/10.1016/S0014-3057(01)00113-6.

17. Ismail, H. \& Jaffei, R. (1997). Curing characteristics and mechanical properties of oil palm wood flour reinforced epoxidized natural rubber composites. International Journal of Polymeric Materials, 36(3-4), 241-254, https://doi.org/10.1080/00914039708029418. 